\title{
Candidatos de origem Japonesa Na POLÍTICA MUNICIPAL PAULISTA, 1947-1964 ${ }^{1}$
}

\author{
Gustavo Takeshy TANIGUTI*
}

\begin{abstract}
RESUMO: Este artigo busca caracterizar as condições que viabilizaram a eleição de filhos de japoneses às esferas de poder e decisão política em municípios do estado de São Paulo entre 1947 (quando ocorrem as primeiras eleições em nível estadual e municipal desde o início do Estado Novo) e 1964 (quando o regime político democrático é interrompido). Foram produzidos dados sobre a ocupação de cargos legislativos (vereador) e executivos (prefeito e vice-prefeito) a partir de dados agregados de eleições, disponibilizados pelo Tribunal Regional Eleitoral/SP. É demonstrada a relação entre candidaturas e recursos relacionais oriundos de espaços sociais étnicos. Estudo de caso foi realizado no município de Bastos-SP.
\end{abstract}

PALAVRAS-CHAVE: Imigração japonesa. Eleições. Japoneses. Inserção política. São Paulo.

\section{Introdução}

Entre os principais fenômenos abordados pela literatura brasileira dedicada aos estudos migratórios - como o preconceito, o racismo, os processos de formação étnico-racial, o empreendedorismo, o associativismo -, o ingresso de imigrantes e seus descendentes na política ainda tem sido pouco avaliado. O estudo desse fenômeno nos fornece subsídios para melhor caracterizar a participação de indivíduos de origem estrangeira em sociedades plurais e democráticas, o que evidencia a trans-

\footnotetext{
IFMG - Instituto Federal de Minas Gerais. Betim - MG - Brasil. 32677-562 - gustavotaniguti@gmail. com. https://orcid.org/0000-0003-3905-5140.

1 Este artigo é resultado de pesquisa financiada pela Fundação de Amparo à Pesquisa do Estado de São Paulo (FAPESP).
} 
formação de barreiras restritivas à inserção desses novos sujeitos nas estruturas de poder. Isso ocorreu com maior vigor no Brasil a partir de meados do século vinte, principalmente quando os resultados dos pleitos municipais foram capazes de alterar o jogo de forças que, durante o regime anterior, havia garantido a permanência de grupos tradicionais na política.

Neste artigo, examino mecanismos que viabilizaram a eleição de candidatos de origem japonesa para cargos municipais no estado de São Paulo entre 1947 (quando ocorreram as primeiras eleições em nível estadual e municipal desde o início do Estado Novo) e 1964 (quando o regime democrático foi interrompido), levando-os, assim, às esferas de poder. Em eleições anteriores a esse período, não há registros de indivíduos dessa origem que tenham ocupado cargos políticos, o que indica a existência de possíveis impedimentos a sua consecução. Esse cenário foi alterado justamente com a retomada das eleições municipais.

É válido notar que, com exceção do trabalho de Kantowicz (1975), o tema da inserção política de imigrantes e descendentes emergiu no debate sociológico apenas no início dos anos 1990, em estudos sobre a sociedade estadunidense (GERSTLE; MOLLENKOPF, 2001). Até então, a bibliografia especializada havia buscado engendrar formas alternativas para se examinar a incorporação estrutural de imigrantes, se interessando por temas como a mobilidade ocupacional ascensional e as formas de inserção no mercado de trabalho. Disso resultaram análises menos tributárias das perspectivas assimilacionistas clássicas e dos modelos econômicos de inspiração push-pull (PORTES, 1981, 1987). Elas ganharam expressão em trabalhos como: Toward a theory of minority-groups relations (BLALOCK, 1967), Ethnic Enterprise in America (LIGHT, 1972), A theory of middleman minorities (BONACICH, 1973) e Longtime Californ' (NEE; DE BARY NEE, 1973).

Já a partir dos anos 1980, perspectivas teóricas renovadas colocaram no centro da discussão os arranjos "étnicos" na organização de atividades econômicas, especialmente, em grandes cidades. Autores passaram, então, a argumentar que a experiência migratória não é sobredeterminada por fatores macroestruturais, mas também, depende de estratégias e recursos relacionais fundamentados na origem compartilhada (PORTES, 2000; PORTES; MANNING, 1986; PORTES; SENSENBRENNER, 1993). Outros trabalhos procuraram desvendar a heterogeneidade das formas de assimilação, segmentadas de acordo com o grupo (PORTES; RUMBAUT, 1990; PORTES; ZHOU, 1993) ou de acordo com a dinâmica espacial da cidade que acolhe o imigrante (SCHILLER, 2008).

Em meio a uma variedade de temas, nas últimas três décadas houve um crescente interesse no estudo da inserção política enquanto parte constitutiva de processos mais gerais de incorporação de imigrantes. O seu exame demanda considerar, por um lado, o modo particular pelo qual cada grupo imigrado, em diferentes regimes políticos, vivencia as condições sociais e institucionais que lhe foram ofertadas 
(GREEN, 2006). Por outro lado, torna imprescindível avaliar o contexto específico em que se estabelece a relação nacional-estrangeiro: "as discussões sobre incorporação de imigrantes sempre se encontram social e historicamente ancoradas sobre as conjunturas enfrentadas pelas sociedades receptoras" (TRUZZI, 2012, p.529).

No Brasil, os estudos sobre inserção política de imigrantes foram inaugurados por pesquisadores ligados ao Instituto de Estudos Econômicos, Sociais e Políticos de São Paulo (IDESP). São exemplos disto as publicações organizadas por Boris Fausto, que incluem estudos sobre sírios, libaneses, armênios, japoneses, alemães e espanhóis (FAUSTO, 1991; FAUSTO et al., 1995). Além do seu ineditismo, essas obras tornaram-se referências por inaugurar uma abordagem inovadora, segundo a qual os imigrantes não são concebidos, apenas, enquanto objetos sob os quais incidem as leis, mas são potenciais protagonistas no campo político (ENNES, 2006). Isso é especialmente válido para o caso paulista, por algumas razões.

Entre os anos de 1882 e 1934, o estado de São Paulo foi o destino da maior parcela $(60 \%)$ dos cerca de oito milhões de estrangeiros que aportaram no Brasil (TRUZZI; KERBAUY; BARBOSA, 2012). Após cerca de dez anos de severas restrições à imigração, o término do Estado Novo possibilitou que a entrada de estrangeiros no país fosse retomada. Iniciou-se, assim, um novo contexto de elaboração de políticas migratórias, ocupação de zonas agrícolas e urbanização. Principalmente, as estruturas de poder sofreram alterações significativas, abrindo caminhos para que imigrantes ocupassem posições sociais de maneira inédita.

Na Quarta República (1945-1964), as instituições públicas de justiça e segurança - que, no regime anterior, haviam sido mobilizadas tendo em vista um maior controle sobre os modos de vida dos imigrantes - tornaram-se, progressivamente, mais receptivas à presença estrangeira no país. Isso pode ser constatado a partir da revogação de antigos decretos restritivos, ou mesmo de iniciativas como a assinatura de acordos migratórios, a criação do Instituto Nacional de Imigração e Colonização (INIC) e o acolhimento de refugiados de guerra.

Ainda assim, para certos grupos como alemães, italianos, judeus e japoneses, a sua aceitação pública e a sua presença no imaginário nacional ainda representavam impasses à espera de solução. Poucos anos antes, esses grupos haviam sido diretamente afetados pela forma coercitiva que a campanha de nacionalização estadonovista assumiu. Somou-se a isso a posição de apoio às Forças Aliadas adotada pelo governo brasileiro durante a Segunda Guerra (COMISSÃO, 1992). Por isso mesmo, a paulatina transformação desse cenário se mostra significativa do ponto de vista da análise, e a inserção política desses grupos é uma forma de observá-la.

Este artigo analisa a inserção política de japoneses e descendentes em um período específico da história republicana. Tal fenômeno acompanhou, de modo geral, os processos de mobilidade socioeconômica que esse grupo experimentou nos 
primeiros cinquenta anos desde o início de sua chegada ao Brasil ${ }^{2}$. Acredito, então, que interpretações atualmente existentes na bibliografia especializada (BERTOLDO, 2018; NAGAMURA, 2015; SAKURAI, 1993, 2005) podem ser complementadas, principalmente, se considerarmos a expressividade de casos situados no interior paulista.

A pesquisa foi conduzida entre 2016 e 2018, no âmbito do projeto "Percursos histórico-sociais na incorporação de imigrantes no Oeste Paulista (1880-1950)", coordenado por Oswaldo Truzzi. Ela teve início com a coleta e análise documental nos arquivos do Tribunal Regional Eleitoral do Estado de São Paulo (TRE/SP). Foram analisadas as legislaturas e, com base na sua composição, foram tabulados os casos de descendentes de japoneses eleitos tanto para cargos legislativos (Vereador) quanto para cargos executivos (Prefeito e Vice-prefeito).

A presença de candidatos de origem nipônica na política teve início com cargos legislativos. Eles foram, inclusive, mais recorrentes se comparados aos cargos executivos. Os dados obtidos nessa etapa inicial nos permitiram produzir mapas que ilustram cômputos de casos referentes a ambos os cargos, segundo resultados agregados de eleições de todos os municípios do estado ocorridos nos seguintes anos: 1947, 1948, 1949, 1951, 1954, 1955, 1957, 1958, 1959, 1961, 1962 e 1963.

A etapa seguinte foi dedicada a averiguar quais elementos próprios à experiência migratória guardam relação com o fenômeno observado. Para isso, foi realizado um estudo de caso no município de Bastos, situado na mesorregião de Marília, na zona Centro-Oeste do estado de São Paulo. Historicamente, esse município concentrou a ocorrência de candidatos eleitos, bem como dispõe de museu especializado. Ali, foi possível consultar registros e documentos em geral pouco acessíveis. Por intermédio da Associação Cultural e Esportiva Nikkey de Bastos, foram realizadas entrevistas com diretores de associações, comerciantes e ex-candidatos japoneses e filhos de japoneses.

Os resultados obtidos pela pesquisa indicam que a inserção política desses candidatos esteve condicionada a variáveis como o timing de chegada do contingente migratório e às estruturas governança vigentes nos locais de destino e origem. Em suas candidaturas, esses candidatos se valeram de recursos relacionais específicos, dentre os quais se destacam capitais econômico, social e educacional. Eles foram, estrategicamente, mobilizados em pleitos municipais, pois serviram como aporte tanto para viabilizar candidaturas quanto para obter resultados favoráveis nas urnas. Tais capitais são específicos, porque foram concebidos em espaços relacionais e em redes associativas próprias ao grupo (BOURDIEU, 1998). Foi, assim, que o associativismo fundamentado na origem compartilhada impactou na composição

\footnotetext{
2 Refiro-me especificamente ao movimento de mobilidade ocupacional ascendente experimentado pelos japoneses entre 1908 e 1958, assinalado por Saito (1961) e pelo survey The Japanese Immigrant In Brazil (SUZUKI, 1969).
} 
de legislaturas, sobrepondo-se até mesmo a variáveis consideradas convencionais, como a orientação política e a filiação partidária.

No período considerado, as candidaturas bem-sucedidas estiveram diretamente relacionadas a estruturas de relações fundamentadas na origem estrangeira. Longe de representarem um universo estático e homogêneo, os espaços relacionais e as redes associativas possuíam uma morfologia complexa, por comportar diferenças internas ao grupo - fossem elas de nacionalidade, idioma, valores, aspirações e costumes. No universo nativo, essas diferenças fomentaram a segmentação geracional entre imigrantes e filhos de imigrantes. Com raras exceções, as candidaturas bem-sucedidas foram protagonizadas por estes últimos, muito embora eles não pudessem dispensar o apoio dos primeiros.

\section{Cargos eletivos municipais no novo regime democrático}

No pleito municipal de 1947, foram eleitos os primeiros políticos de origem japonesa. À época, tratava-se de uma novidade surpreendente, haja vista certos desdobramentos decorrentes do fim da Segunda Guerra. Em 1946, a imprensa passou a noticiar a emergência de organizações ultranacionalistas japonesas, responsáveis por promover atentados e assassinatos por motivações políticas e ideológicas ${ }^{3}$. Elas estavam, diretamente, relacionadas à negação da derrota do império japonês no conflito bélico.

Um caso emblemático foi o assassinato do diretor da Cooperativa Agrícola de Bastos, Jinsaku Wakiyama, em julho daquele ano. Eventos como esse foram, amplamente, reportados pela imprensa paulista e provocaram reações nos próprios imigrados e no restante da população brasileira - bem como desencadearam a vigilância pelas autoridades policiais. Além disso, eles acabaram por fortalecer, ainda mais, a produção de estigmas e intolerância agravados por diferenças linguísticas, culturais e fenotípicas (COMISSÃO, 1992; DEZEM, 2000; HATANAKA, 1993; WILLEMS; SAITO, 1947). A eleição de candidatos de origem japonesa teve início, justamente, nessa referida conjuntura: um ambiente tensionado por nacionalismos conflitantes, em que a rejeição à figura do japonês por grupos nativos era frequente.

Muito embora esse fenômeno possa aparentar uma possível contradição, qualquer estudo que vise o seu exame deve considerar que as formas de controle e coerção exercidas pelo Estado brasileiro coexistiram com certas oportunidades ofertadas aos estrangeiros. Algumas delas encontraram expressão, por exemplo, no universo econômico, acompanhando um movimento planejado de estímulo à

\footnotetext{
3 A relação completa dos atentados e a descrição dos grupos ultranacionalistas podem ser encontrados em: COMISSÃO DE ELABORAÇÃO DA HISTÓRIA DOS 80 ANOS DA IMIGRAÇÃO JAPONESA NO BRASIL. Uma epopeia moderna: 80 anos da imigração japonesa no Brasil. Hucitec, 1992.
} 
diversificação e à modernização da produção agrícola por meio de leis, de concessão de incentivos fiscais, de realização de obras de infraestrutura e da criação de órgãos públicos de suporte e fiscalização da produção.

No caso dos japoneses, essas condições facilitaram o desenvolvimento de empreendimentos associativos, com destaque para as cooperativas. Além disso, a criação de novos territórios político-administrativos em nível municipal forneceu as bases institucionais para a composição de quadros políticos locais que esse grupo passou a experimentar no novo regime.

Na literatura especializada, há consenso em se afirmar que a Constituição de 1946 trouxe novidades quanto ao exercício dos direitos civis ao instaurar as bases legais da Quarta República. Sob forte influência de um léxico trabalhista e do discurso da "democracia racial" (GUIMARAES, 2006), partidos com programas ideológicos definidos e identificados com o eleitorado puderam se reorganizar. A despeito de os mandatos presidenciais terem sofrido com a instabilidade política (AVRITZER, 2018), foi concreta a possibilidade de maior participação de grupos sociais que, até então, haviam contado com pouca ou mesmo nenhuma representatividade.

Logo após o término da Segunda Guerra, a reorganização política já era considerada no debate público um processo inescapável no Brasil, a exemplo dos decretos que dispuseram sobre o pluripartidarismo e a convocação de eleições. Eles foram significativos para filhos de imigrantes, pois viabilizaram, do ponto de vista regulatório, as suas aspirações de ingresso no universo da política.

Com o término do Estado Novo em outubro de 1945, assumiu a presidência interina da República o presidente do Supremo Tribunal Federal, José Linhares. As eleições para presidente e para deputados e senadores para a composição da Assembleia Nacional Constituinte ocorreram em seguida, no mês de dezembro. Eurico Gaspar Dutra foi eleito presidente e, no caso de São Paulo, houve disputa pelas 35 cadeiras reservadas ao estado. Em setembro do ano seguinte, foi promulgada a Constituição Federal. A transição democrática se completou em 1947 com dois pleitos: o primeiro ocorrido no mês de janeiro, para governadores, deputados e senadores das Assembleias Constituintes estaduais. O segundo pleito ocorreu em novembro para preenchimento dos cargos municipais. Em São Paulo, foram disputados os cargos de vereador nas câmaras de 305 municípios e o cargo de prefeito em 292 deles (MANECHINI, 2012).

Esse novo cenário trouxe possibilidades inéditas a filhos de imigrantes no estado de São Paulo, o que, de uma forma geral, pode ser entendido enquanto parte significativa de um movimento mais amplo em curso desde 1930. A reconfiguração do sistema político acarretou, entre outros aspectos, a renovação das elites de poder tradicionais e o fim das interventorias (CODATO, 2008; TRUZZI, 2009). Estas últimas eram uma estrutura burocrática estatal centralizadora que legislava nas 
matérias de competência do estado e dos municípios por meio do Departamento Administrativo do Serviço Público (DASP), representante do poder federal. Subordinados às interventorias, os prefeitos municipais se submetiam tanto ao interventor do estado (que os nomeava) quanto ao presidente do Departamento Estadual do Serviço Público, possuindo, portanto, uma atuação limitada (SOUZA; KERBAUY; TRUZZI, 2003). A extinção definitiva desse sistema permitiu que japoneses nacionalizados, ou seus filhos nascidos no Brasil, concorressem pela primeira vez a cargos eletivos.

\section{A inserção política de candidatos de origem japonesa}

Diferente de outros grupos imigrados que elegeram candidatos no pleito municipal de 1936 (o último antes do Estado Novo), como os italianos, portugueses, suíços, sírios e libaneses, a primeira oportunidade efetiva em que filhos de japoneses concorreram às eleições municipais foi no pleito de novembro de 1947. Enquanto a eleição do cargo de prefeito ocorria pelo voto direto, a dos representantes do poder Legislativo obedecia ao sistema proporcional.

Entre os candidatos de origem japonesa, um caso tornou-se emblemático no contexto das eleições municipais ocorridas em 1947: o advogado "Luís" Yukishigue Tamura assumiu o cargo de vereador do município de São Paulo em fins daquele ano, beneficiado pela cassação dos candidatos do Partido Social Trabalhista (PST), por decisão do Tribunal Superior Eleitoral ${ }^{4}$ (BAUAB, 2012). Para além das manobras eleitorais resultantes do jogo de poder e de forças políticas que culminou com a cassação de candidatos eleitos democraticamente, a posse de um cargo político trouxe a Tamura grande visibilidade entre a população japonesa que habitava a capital paulista (SALVADORI FILHO, 2014).

Contudo, diferente do que afirma a literatura, Tamura não foi o primeiro descendente de japoneses eleito para um cargo político. Naquele pleito de 1947, outros trinta e sete candidatos de origem japonesa, também, haviam sido eleitos para cargos legislativos em municípios do interior paulista - fato que, até os dias atuais, não foi examinado por pesquisadores, com exceção do trabalho de Nagamura (2015).

É bem possível que a notoriedade alcançada por Yukishigue Tamura contribuiu para que o pioneirismo lhe fosse atribuído sem grande dissenso. Afinal, ele passou a representar uma espécie de trajetória exemplar para uma segunda geração de imigrantes, que aspirava a ascensão social e a aceitação de suas diferenças. Após

\footnotetext{
4 Somente no município de São Paulo, 15 vereadores do Partido Social-Trabalhista (PST) foram cassados na véspera da tomada de posse dos seus cargos.
} 
ocupar sucessivos cargos políticos, Tamura conquistou amplo reconhecimento social e era considerado uma figura pública notável. Um ponto crítico a ser destacado é que na escassa literatura dedicada ao exame da ascensão política de indivíduos de origem japonesa no Brasil, autores constantemente reproduzem uma narrativa de pioneirismo na política que Tamura supostamente teria protagonizado (SAKURAI, 1993; SALVADORI FILHO, 2014). Desse modo, a centralidade conferida ao pleito ocorrido na capital paulista contribuiu para a omissão de casos situados em outras localidades.

Tendo em vista a superação dessas limitações, enfatizo que a produção e a análise de novas evidências empíricas que contemplem municípios do interior paulista podem contribuir para a produção de novos entendimentos sobre o fenômeno em discussão. Seguindo essa proposta, as figuras a seguir ilustram a distribuição dos candidatos de origem japonesa eleitos para ambos os cargos legislativo e executivo em municípios paulistas, por período.

Figura 1 - Distribuição dos candidatos de origem japonesa eleitos em municípios paulistas, 1947-49.

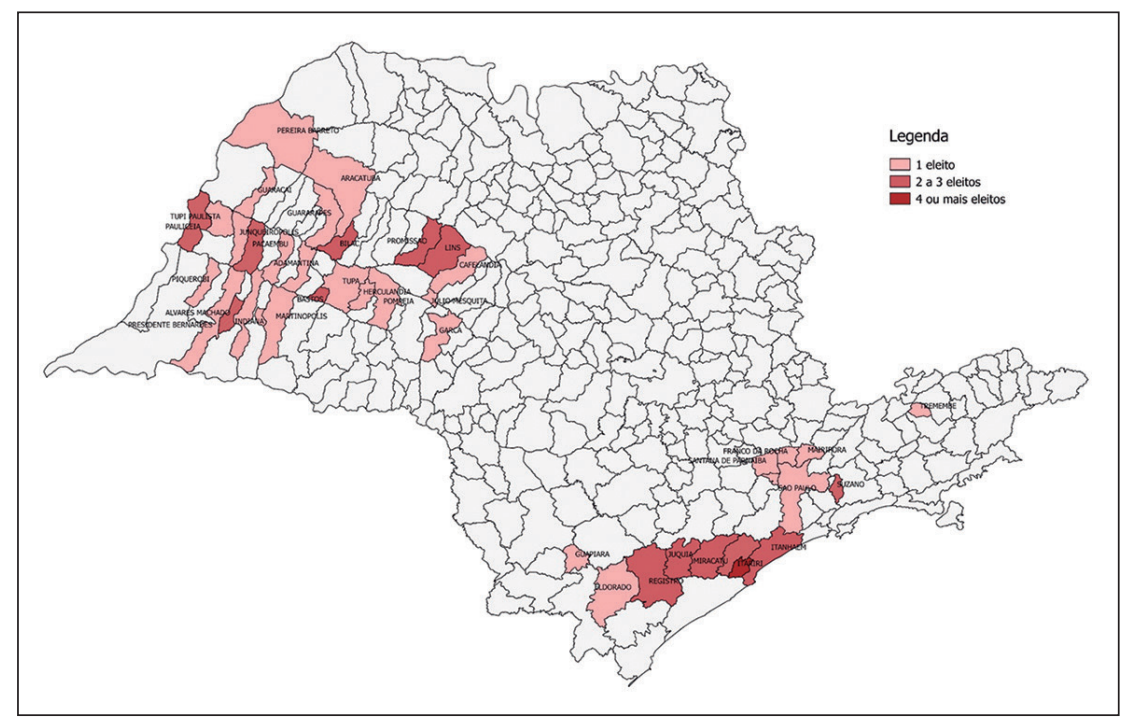

Fonte: Elaboração própria a partir de dados do TRE/SP. 
Figura 2 - Distribuição dos candidatos de origem japonesa eleitos em municípios paulistas, 1950-54.

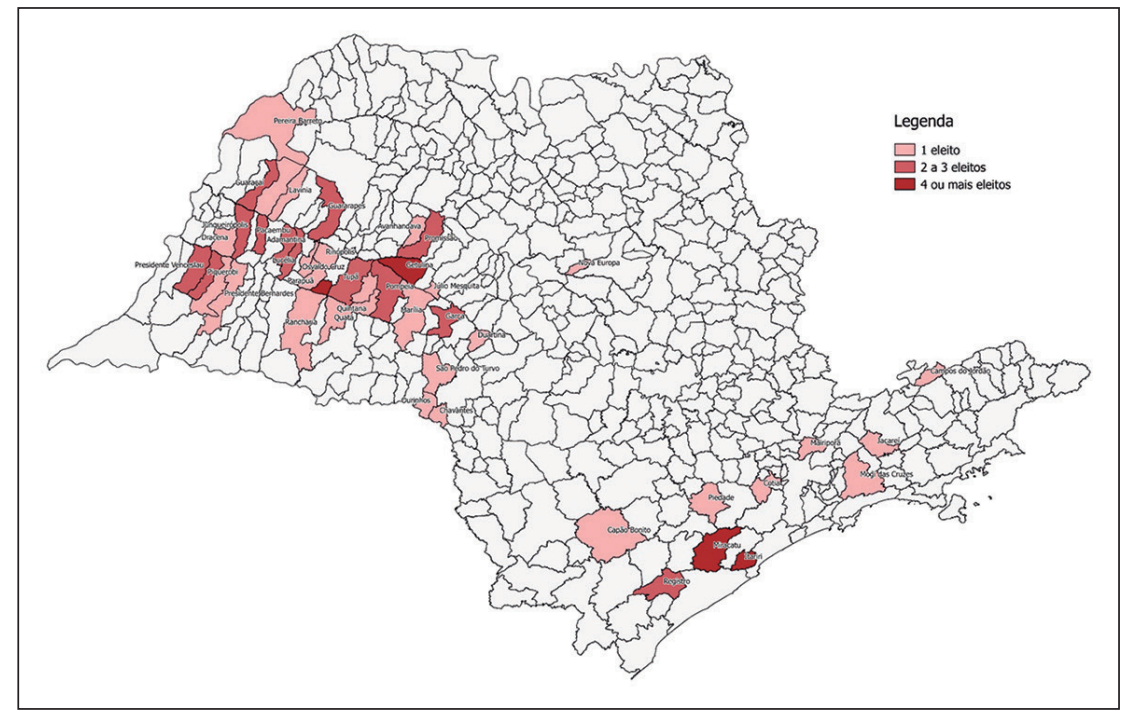

Fonte: Elaboração própria a partir de dados do TRE/SP.

Figura 3 - Distribuição dos candidatos de origem japonesa eleitos em municípios paulistas, 1955-58.

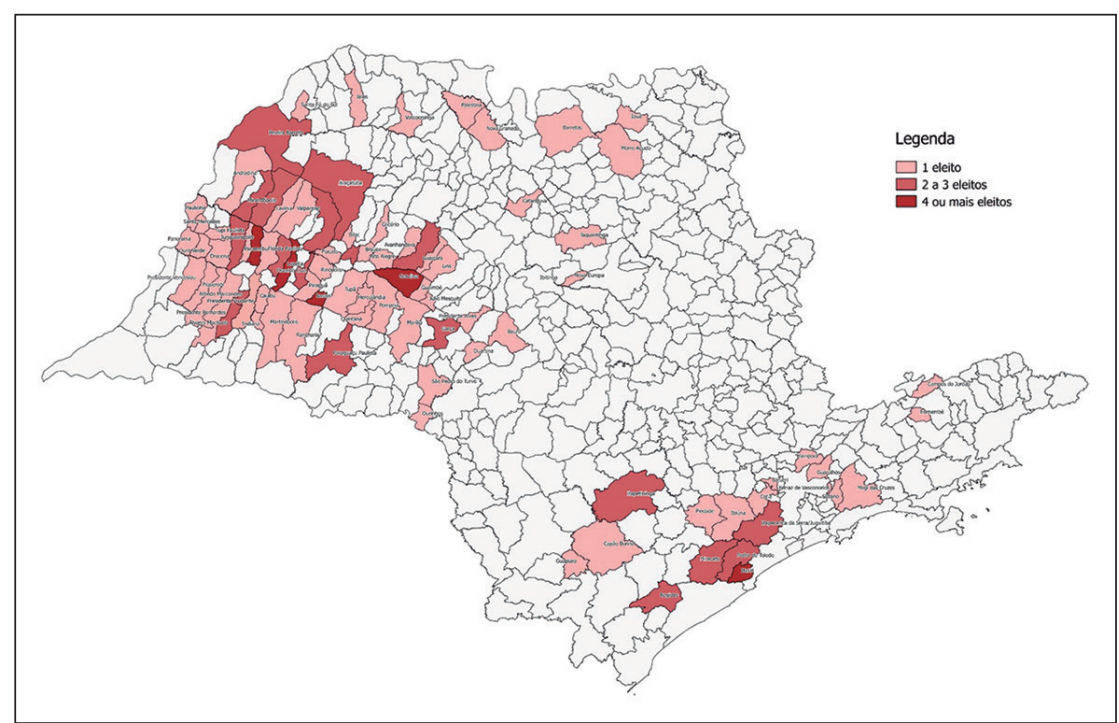

Fonte: Elaboração própria a partir de dados do TRE/SP. 
Figura 4 - Distribuição dos candidatos de origem japonesa eleitos em municípios paulistas, 1959-62.

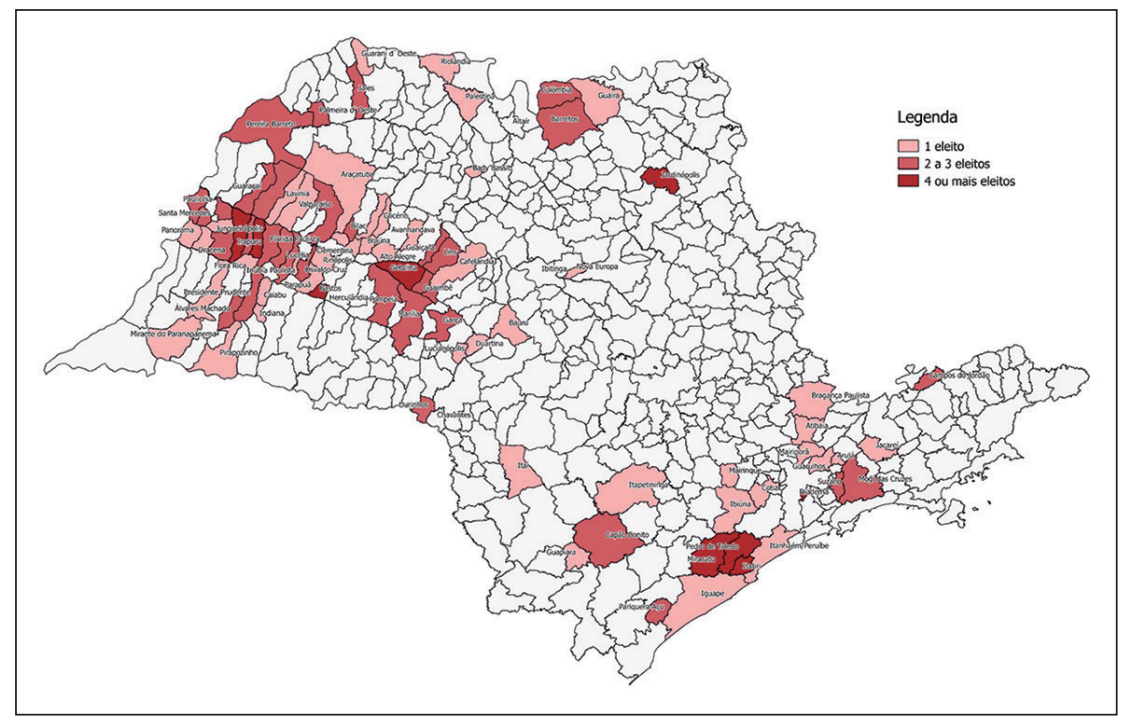

Fonte: Elaboração própria a partir de dados do TRE/SP.

\section{Breve descrição dos casos}

De um modo geral, os casos dos candidatos de origem japonesa eleitos concentraram-se em municípios e zonas do estado com maior presença desse grupo. Possuem destaque as zonas Noroeste, Alta Paulista, Vale do Ribeira e Região Metropolitana de São Paulo. Verifica-se essa correspondência a partir da figura a seguir, que mostra a distribuição da população japonesa ao longo do tempo segundo zonas agrícolas. 
Figura 5 - Distribuição da população japonesa por zona e período.

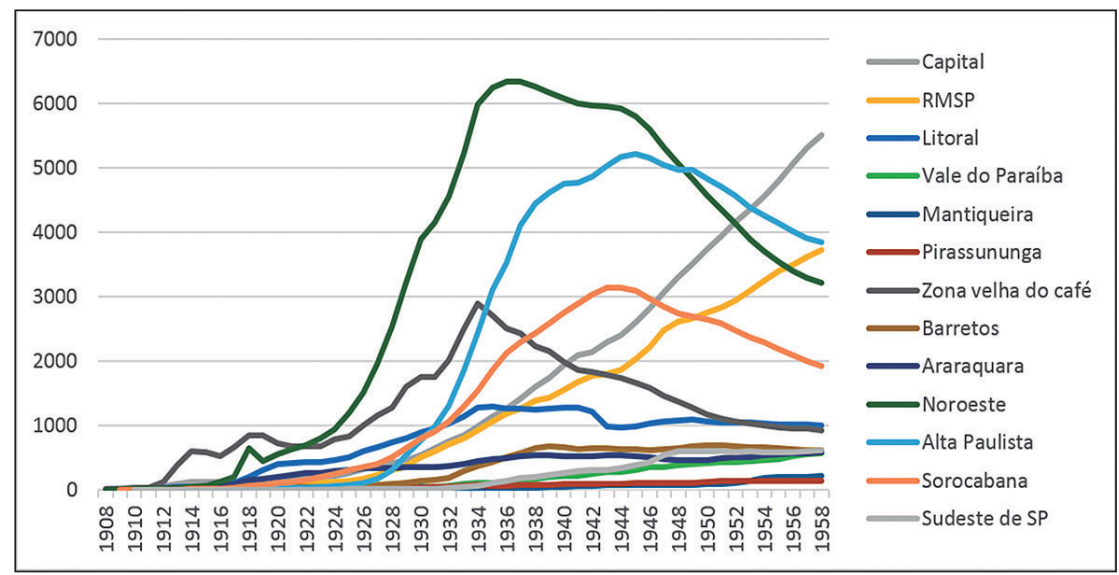

Fonte: Elaboração própria a partir de Suzuki (1969, p.426), tabela 335.

Entre 1947 e 1949, foram eleitos 62 candidatos de origem japonesa em 42 diferentes municípios do estado de São Paulo, principalmente, aqueles localizados na Zona Oeste. Entre eles, possuem destaque Bilac, situado na Mesorregião Araçatuba, com 3 vereadores eleitos ${ }^{5}$ e Itariri, situado na Mesorregião do Vale do Ribeira, com 5 vereadores eleitos ${ }^{6}$. A ocorrência de três eleições municipais em um período de três anos deveu-se, principalmente, à fundação de 64 novos municípios no período. Assim, em muitos deles, essas eleições estabeleceram a disputa para a composição da primeira Legislatura de suas Câmaras Municipais. Os cargos legislativos, inclusive, não eram remunerados.

Nos pleitos municipais de 1951, 1952 e 1954 houve uma novidade, estabelecida a partir da Lei $n^{\circ} 1.174$, de 21/08/1951: a criação do cargo de vice-prefeito, a ser eleito por voto direto. Em casos excepcionais (geralmente, em municípios que tiveram eleições em 1949), o vice-prefeito era escolhido por voto indireto da Câmara. É o caso de Júlio Mesquita, situado na Mesorregião de Bauru, que teve 1 vice-prefeito ${ }^{7}$ de origem japonesa a partir da aplicação dessa lei. Os dados referentes ao período entre 1951 e 1954 indicam uma tendência de aumento do número de casos de eleitos. Em 45 municípios em que houve ocorrência, foram eleitos ao total 72 candidatos. Possuem destaque os municípios de Bastos, na Mesorregião de

\footnotetext{
5 Tiosuke Sakamoto, Massami Sasahi e Massatoshi Onohara. Eleições de 9/11/47.

6 Ari Tomio Miaciro, José Higa, José Choqui Tamaguski, Heicho Fukuti e Yonemori Taira. Eleições de $13 / 03 / 49$.

7 Hakuo lamamoto.
} 


\section{Gustavo Takeshy Taniguti}

Marília, com 4 vereadores e 1 vice-prefeito eleitos ${ }^{8}$, e Miracatu, na Mesorregião do Vale do Ribeira, com 5 vereadores eleitos 9 .

Nos pleitos municipais de 1955, 1957 e 1958, é possível observar que houve um aumento significativo no número de ocorrências, principalmente, nas mesorregiões de Presidente Prudente e Araçatuba. Pela primeira vez, houve casos na zona Norte do estado, na mesorregião de São José do Rio Preto (Jales, Palestina, Nova Granada) e na mesorregião de Ribeirão Preto (Barretos, Morro Agudo, Ipoã). Em 83 municípios em que houve ocorrência, foram eleitos 120 candidatos. Possuem destaque os municípios: Bastos, com 7 vereadores ${ }^{10}$ e 1 prefeito (Tadao Hatanaka, o primeiro de origem japonesa a ser eleito em todo o estado), Pacaembu, na mesorregião de Presidente Prudente, com 5 vereadores eleitos ${ }^{11}$, e Pauliceia, na mesorregião de Presidente Prudente, com 1 prefeito eleito ${ }^{12}$.

Nos pleitos municipais de 1959, 1961 e 1962, uma novidade que acompanhou essas eleições: a nova distribuição territorial do estado a partir da Lei ${ }^{0} 5.285$, de 18/02/1959, que estabeleceu a divisão em 195 comarcas, 505 municípios e 841 distritos. Assim como no período anterior, houve ocorrência em 83 municípios e foram eleitos 150 candidatos de origem japonesa. Os dados colhidos indicam que o número de ocorrências continuou em ritmo crescente, porém com uma tendência maior à diversificação das regiões. Além disso, identificamos um número maior de municípios em que 4 ou mais candidatos de origem japonesa foram eleitos no mesmo pleito. São os casos das eleições de 4/10/1959 em Diadema ${ }^{13}$ (Região Metropolitana de São Paulo), Miracatu ${ }^{14}$ (Mesorregião do Litoral Sul), Osvaldo Cruz $^{15}$ (Mesorregião de Presidente Prudente) e Bastos (Mesorregião de Marília). Se comparado aos períodos anteriores, houve, também, um aumento na eleição para cargos executivos municipais, de prefeito e vice-prefeito, totalizando três municípios: Diadema (vice-prefeito), Miracatu (vice-prefeito) e Bastos (prefeito). Neste último, 8 das 11 vagas de vereadores foram ocupadas por candidatos de origem japonesa ${ }^{16}$ e a isso se somou a vaga de prefeito, ocupada por Tohoru Nishi, totalizando 9 candidaturas eleitas no mesmo pleito.

\footnotetext{
8 Hiroko Ikeda, Kiyussuki Sasaki, Luiz Misuko Ikeda, Massaro Makimori, Paulo Seizi Zakimi (viceprefeito).

9 Ushima Hirroski, Seijo Onaga, Takasigue Yamashiro, Carlos Hirakawa. Na página oficial da Câmara do município consta além desses nomes Joaquim Shimabukuro, possivelmente eleito por suplência.

${ }^{10}$ Atsushi Taniguchi, Hirayuki Kobayashi, Luiz Misuko Ikeda, Mamoru Taroda, Paulo, Seizi Zakimi, Toboru Nishi, Vitório Higashi. Eleições de 03/10/1955.

11 Ioshito Kawaguti Mário Kawakami, Sadao Tashiro, Tomo Hirozo, Tossio Shigueta. Eleições de 10/03/1957.

12 Kiro Sentaro. Eleições de 10/03/1957.

${ }_{13}$ Orlando Okazaki (vice-prefeito), Mituo Mizobuti, George Goro Kuroiwa, Giutaro Tanaka.

${ }_{14}$ Takasique Yamashiro (vice-prefeito), Paulo Kamia, Seijo Onaga, Sisei Toma.

15 Giro Kuniyoshi, João Nagano, João Matushita (assumido por suplência).

${ }^{16}$ Hirayuki Kobayashi, Tomoya Shida, Tadao Hatanaka, Mamoru Taroda, Atsushi Taniguchi, Massaharu Matsubara, Toshio Goto, Hitoshi Ono.
} 
Nas eleições ocorridas em 5 e 23/03/1961, sete municípios elegeram 3 ou mais candidatos de origem japonesa: Suzano ${ }^{17}$ (Região Metropolitana de São Paulo), Pedro de Toledo ${ }^{18}$, Juquiá ${ }^{19}$ e Itariri $^{20}$ (na Mesorregião do Litoral Sul), Junqueirópolis ${ }^{21}$ e Pacaembu ${ }^{22}$ (Mesorregião de Presidente Prudente) e Julio Mesquita $^{23}$ (Mesorregião de Bauru). Em Pacaembu e Juquiá foram eleitos vice-prefeitos. No período compreendido, entre 1959 e 1962, foram eleitos, portanto, 4 vice-prefeitos e 1 prefeito de origem japonesa.

Esse quadro geral me levou a averiguar quais variáveis foram significativas para a ocorrência do fenômeno em questão. Longe de esgotar as possibilidades existentes, em um primeiro momento da pesquisa, optei por enfatizar a relevância de certas variáveis que, do ponto de vista da análise, operaram em nível macro. Elas forneceram as condições mais gerais para que indivíduos e grupos estrangeiros se estabelecessem no território nacional em contextos específicos de elaboração de políticas migratórias, de ocupação de zonas agrícolas, de desenvolvimento econômico regional. São considerados relevantes o momento histórico de chegada do contingente japonês e as estruturas de governança vigentes nos diferentes regimes políticos da sociedade brasileira.

\section{Presença governamental das nações de origem e destino}

Diferente de outros países do continente americano, os japoneses chegaram ao Brasil no começo do século vinte e o auge dessa imigração ocorreu na década de $1930^{24}$. Após o término do financiamento integral dos custos de viagem pelo Governo do Estado de São Paulo em 1920, o governo japonês financiou a vinda de seus cidadãos entre 1925 e 1940, principalmente através do Kaigai Kougyou Kabushiki Kaisha, órgão executivo de emigração criado em 1917 (NOGUEIRA, 1973). A partir de 1923, o Brasil era, praticamente, o único país que ainda recebia imigrantes japoneses e, nesse período, esse órgão encaminhou cerca de 164.000 indivíduos, configurando o auge da entrada dessa nacionalidade no país.

Na segunda metade da década de 1920, o suporte do governo japonês reverberou no destino dos imigrados, de forma que a produção cafeeira em grandes fazendas deixou de ser um destino exclusivo. Em 1929 foi criada a Sociedade

\footnotetext{
17 Julio Ossamu Yokoama, Hojumi Ikeda, Massashi Nagai.

${ }_{18}$ Antonio Hideo Matsuda, João Akamine, Yoneo Shimabukuro, Jorge H. Tamashiro.

19 José Miadaira (vice-prefeito), Hitoshe Omiya, Mario Tamada, Seiski Hanashiro.

${ }^{20}$ Fumikio Kogashi, Feiyu Fukuti, Nivio Matsushita, Takecatsu Tamaciro, João Higa.

${ }^{21}$ Hidesuke Yagi, Kunitoshi Yamada, Tsunetoshi Sakae, Hanabo Koshiy, Pedro Mitio Matsubara.

22 Sadao Tashiro (vice-prefeito), Shigueo Takahashi, Takeshi Okamoto, Tomo Hirozo, Yoshio Kawaguti.

${ }^{23}$ Akirou Maeda, Tsuguo Noguti, Osvaldo Minoru Miura.

${ }^{24}$ Entre 1930 e 1940 cerca de 100.000 imigrantes japoneses entraram no Brasil (LEVY, 1974).
} 
Colonizadora do Brasil (Bratac), que adquiriu terras em São Paulo e no Paraná para fundar núcleos agrícolas, atuando como entidade central unificadora das colônias japonesas em fase de formação. Sumariamente, a formação de colônias assumia diversas modalidades (SAITO, 1961).

Uma modalidade delas tinha início com a aquisição de lotes de terras (em geral matas virgens) de grandes propriedades. A formalização dos lotes em caráter de exploração atraía imigrantes pioneiros dispostos a torná-los aptos à produção, o que agregava valor à terra para futura revenda. Este tipo de formação foi denominado shokuminchi (colônias), que não pressupunha o estabelecimento definitivo dos colonos (COMISSÃO, 1992). Outra forma bastante comum era feita por empresas privadas: a aquisição dos lotes pelos colonos ocorria ainda no Japão e, posteriormente, se planejava a emigração. Essa modalidade era denominada $i j \hat{u}$-chi (terra para onde se emigrou). Nela, muitos dos imigrantes eram proprietários das terras e estavam decididos a se estabelecer definitivamente no Brasil. É o caso do núcleo colonial de Bastos.

Assim, de modo sucinto, é possível afirmar que o início da imigração japonesa no Brasil esteve, diretamente, relacionado a projetos de colonização que buscavam atrair mão de obra estrangeira para as lavouras de café. Posteriormente, essa dinâmica foi alterada tendo em vista alternativas ao sistema monocultor. Isso significa que a emigração para o Brasil ocorreu não somente enquanto política de Estado por parte do Japão, mas que a sua tutela se fez presente por meio de arranjos institucionais nos locais de estabelecimento - o que singulariza esse grupo em relação aos demais. A forte presença estatal no planejamento e execução dos projetos migratórios, e o seu alto grau de institucionalização tiveram efeitos nas chances de mobilidade socioeconômica dos japoneses. A isso se somou a criação de empreendimentos associativos voltados à distribuição da produção: as cooperativas agrícolas.

\section{A emergência das cooperativas agrícolas}

Entre 1908 e 1941, a presença estatal japonesa foi centralizada pelo Consulado Geral do Japão em São Paulo que, inclusive, estimulou a formação de cooperativas agrícolas. Isso impactou de maneira considerável nas chances de sucesso de colônias estabelecidas após a segunda metade da década de 1920. Naqueles anos, no estado de São Paulo, o sistema cooperativista disseminou-se entre os imigrados, fortemente estimulado pelas seções consulares, que prestavam apoio administrativo e dispunham de crédito financeiro.

Esse sistema havia sido implantado com relativo sucesso no Japão, onde, cerca de $42 \%$ das famílias daquele país estavam associadas a cooperativas (SAITO, 1961). Seguindo essa política de incentivo ao associativismo, em 1934 foi criada 
a Cooperativa Central Nipo-Brasileira, uma espécie de federação cujo escritório funcionava junto ao Consulado e que, até 1941, centralizou a administração de questões jurídicas e burocráticas das cooperativas japonesas existentes em São Paulo (TANIGUTI, 2019).

Mesmo encontrando dificuldades de se adequar ao sistema jurídico brasileiro ${ }^{25}$, ao final da década de 1930, era possível contabilizar a existência de vinte e três cooperativas de origem japonesa, compostas por cerca de cinco mil cooperados (SAITO, 1961; SEABRA, 1977; TANIGUTI, 2019). Em linhas gerais, a adoção do sistema de produção agrícola cooperativista não representou algo inédito para os japoneses, mas estes se beneficiaram tanto do suporte consular do seu país de origem quanto do estímulo à diversificação e desenvolvimento agrícola promovido em nível nacional e estadual.

Já o Estado brasileiro passou a oferecer oportunidades por meio da criação de leis trabalhistas e órgãos setoriais, do estímulo à diversificação da produção agrícola e da criação de uma legislação específica para o cooperativismo. A condição de arrendatário ou proprietário de terras se tornou obrigatória para a participação em cooperativas agrícolas (Decreto-Lei 22.239 de 19 de dezembro de 1932).

Do ponto de vista ocupacional, a população japonesa vinha seguindo uma tendência de ascensão mediante a aquisição de pequenas propriedades rurais. Isso se deveu, basicamente, à concentração de sua atividade econômica no setor agrícola, à migração interregional e mudanças do tipo de produção. Em grande medida, esse grupo passava cada vez mais a se dedicar à produção agrícola diversificada em pequenas propriedades rurais. Portanto, as cooperativas agrícolas operaram como um facilitador dos movimentos de mobilidade ocupacional ascendente da população japonesa no Brasil (SUZUKI, 1969; TANIGUTI, 2014).

Além de suas características estritamente objetivas de atuação no mercado, a forma de organização cooperativista representou para os japoneses uma espécie de referência cultural. A depender de sua dimensão, ela operava na condição de um importante espaço de sociabilidade, de difusão de informações e recursos. Ela congregara circuitos de elites econômicas, políticas e de lideranças locais, e oferecia serviços beneficentes e assistenciais aos seus membros. O desenvolvimento exitoso das cooperativas permitiu a gestação de novos valores que, em seu conjunto, ajudaram na formatação de um ambiente caracterizado por maior aceitação dos japoneses na sociedade local - uma espécie de credencial para a sua incorporação em instâncias variadas da vida social. Devido à sua posição de relativo destaque entre os núcleos coloniais, Bastos passou a integrar essa rede de lideranças oriundas de cooperativas, conforme nos mostra a Figura 6. ${ }_{25}$ Em 1934, das 35
(SEABRA, 1977). 
A agricultura, além de constituir um domínio central em que se operou a inserção social e econômica de uma parcela considerável desse grupo, também, foi transformada em um produto imagético compartilhado, referente a valores positivos associados aos japoneses e ressignificada no novo regime político da Quarta República. A partir do intervalo democrático, portanto, o processo de transposição de fronteiras impeditivas aos japoneses esteve associado de maneira significativa ao universo agrícola. Partindo dessa afirmação, acredito ser possível formular interpretações renovadas a respeito do fenômeno da inserção desse grupo nas estruturas locais de poder.

Figura 6 - Reunião de gestores de cooperativas, realizada em Bastos, década de 1940. Na primeira fileira, sentados e identificados: Ikuta Mizobe, Kenkiti Simomoto e Jinsaku Wakiyama.

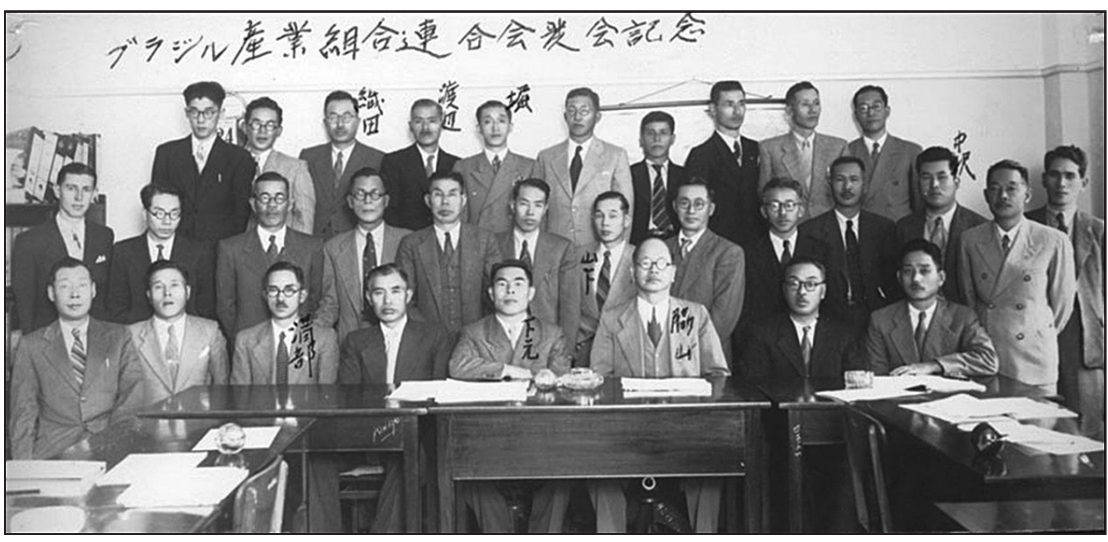

Fonte: Associação Cultural e Esportiva Nipo-Brasileira de Bastos.

\section{Bastos: um epicentro de acontecimentos políticos}

A representatividade de casos situados no município de Bastos me conduziu ao seu exame detido. No período considerado, nenhum outro município elegeu mais candidatos de origem japonesa nos pleitos municipais. E, de modo paradoxal, é válido destacar que no ano anterior às eleições de 1947, Bastos foi um dos epicentros de conflagrações envolvendo atentados cometidos por japoneses ultranacionalistas contra seus compatriotas. Esses indivíduos explicitavam a sua recusa em adotar o modo de vida brasileiro, pois se identificavam com o sistema japonês de valores (Nippon Seishin) e pregavam devoção e submissão ao seu regime. Com isso, aguardavam reconhecimento do Império, que promoveria o seu retorno. A notícia da derrota japonesa na Segunda Guerra foi negada por essa fração de imigrantes e 
desencadeou inúmeras ações de retaliação contra aqueles que assumiam a derrota. Elas envolveram intimidação, ameaças e, também, os assassinatos de lideranças locais - muitos dos quais ocupavam cargos em cooperativas.

Bastos é um município paulista originado a partir de uma colônia de imigrantes ali instalada em fins da década de 1920, sob administração da já referida empresa Bratac. A despeito de a sua fundação, historicamente, ser datada de 1928, foi, somente, em novembro de 1944 que Bastos alcançou autonomia administrativa municipal e o seu primeiro prefeito, Marciliano Aires Júnior, foi eleito indiretamente e cumpriu mandato até 1946. Em 9 de novembro de 1947, foram realizadas eleições municipais para o preenchimento dos cargos legislativos e executivos. Dos treze cargos de vereadores, dois foram ocupados por indivíduos de origem japonesa.

Nos pleitos seguintes, a presença desses candidatos tornou-se recorrente, inclusive para cargos do Poder Executivo: em 1951 eles contabilizavam quatro dos onze vereadores eleitos, além de contar com um vice-prefeito. Em 1955, foram sete dos onze vereadores eleitos além do prefeito que, conforme já foi indicado, foi pioneiro em todo o estado de São Paulo. Já nos pleitos de 1959 e 1963, a quase totalidade dos vereadores possuía origem japonesa, além do prefeito. O quadro a seguir apresenta a composição das legislaturas do município no período considerado pela pesquisa.

Quadro 1 - Composição das legislaturas do município de Bastos, 1947-1963

\begin{tabular}{|llll|}
\hline \multicolumn{2}{|c}{1 1952-55 } & \multicolumn{1}{c|}{$1956-1959$} & \multicolumn{1}{c|}{$1960-63$} \\
\hline Dimas da Silva Rocha (prefeito) & Lino de Lorena Peixoto (prefeito) & Tadao Hatanaka (prefeito) & Tohoru Nishi (prefeito) \\
Coiti Mori & Hiroko lkeda & Atsushi Taniguchi & Atsushi Taniguchi \\
Paulo Seizi Zakimi & Kiyussuki Sasaki & Hirayuki Kobayashi & Hirayuki Kobayashi \\
João Batista Nogueira & Luiz Misuko lkeda & Luiz Misuko lkeda & Hitoshi Ono \\
Augusto Gomes de Oliveira & Massaro Makimori & Mamoru Taroda & Mamoru Taroda \\
Osóio Carnevalli & Paulo Seizi Zakimi & Paulo Seizi Zakimi & Massaharu Matsubara \\
Valdevino Fernandes & Alfredo Veronezi & Tohoru Nishi & Tadao Hatanaka \\
Vergilio Pegini & Antenor Vieira de Sá & Vitório Higashi & Tomoya Shida \\
Manoel de Barros Cavalcanti & Dimas da Silva Rocha & Amílcar Rocha & Toshio Goto \\
João Mancilha Pinto & Euzébio José Tolentino & Antenor Vieira de Sá & Augusto Gomes de Oliveira \\
Demóstenes Pereira de Castro & José Marques Válio & Issac de Andrade Freitas & João Baptista Nogueira \\
José Marques Válio & Maria Aparecida Rocha & Lino de Lorena Peixoto & Ozório Carnevalli \\
Emídio de Adrade Freitas & Ozório Carnevalli & & \\
Luciano Miquelon & & & \\
\hline
\end{tabular}

Fonte: Elaboração própria a partir de dados do TRE/SP. 


\section{A presença japonesa em Bastos}

Em 1928, Mitsusada Umetani, ex-governador da província de Nagano, atuava como o diretor-executivo do órgão japonês nomeado Confederação das Cooperativas de Emigração para o Ultramar. Ele foi incumbido da tarefa de adquirir terras para o estabelecimento de colônias nos estados de São Paulo e Paraná, o que foi feito em 1928. Foram adquiridas quatro propriedades que deram origem às seguintes colônias: Bastos (12 mil alqueires), Nova Aliança (Mirandópolis, 1,3 mil alqueires), Tietê (Pereira Barreto, 46,6 mil alqueires) e Três Barras, no Paraná (atual Assaí, 12,5 mil alqueires).

No caso de Bastos, Umetani contou com o auxílio de Senjiro Hatanaka, funcionário do setor de imigração do Consulado Geral do Japão em São Paulo, e Tokuya Koseki, do setor de saneamento. Concebido para ser um núcleo colonial planejado, Bastos teve a sua data de fundação estabelecida no dia 18 de junho de 1928 (mesmo dia da chegada dos primeiros imigrantes japoneses no Brasil, vinte anos antes), quando foi assinado o contrato de compra de uma fazenda de propriedade de Henrique Bastos Thompson.

Ao total, doze províncias japonesas aderiram ao projeto e passaram a enviar imigrantes para o local a partir de 1929. A gestão dos núcleos ficou a cargo da Bratac e, partir de então, foram demarcadas áreas de produção, divididas em seções (Alto, Esperança, Saúde, Progresso, Glória, União, Cascata, Bonfim, Fartura). Após a superação de certos empecilhos relativos à administração dessas seções e da vinda de imigrantes, inicialmente, os colonos se dedicaram ao cultivo do café e do algodão (BASTOS, 2011).

Em 1932, a Bratac passou a estimular a sericicultura e, para isso, construiu uma fábrica de fiação de seda e outra de beneficiamento de algodão no local. Isso impulsionou a economia do núcleo colonial, tornando Bastos um dos principais produtores de fios seda do país. Em 1937, a Confederação das Cooperativas de Emigração para o Ultramar foi transformada em uma empresa de capital aberto, o que trouxe novas possibilidades de investimento. Sob administração do gestor Kunito Miyasaka, a Bratac recebeu considerável investimento privado. Já a população do município, que em 1930 era composta por cerca de 6 mil habitantes, praticamente havia dobrado em 1945.

\section{Associativismo e formação de lideranças}

A guerra trouxe mudanças significativas para a realidade da população japonesa residente em Bastos. Nas empresas de capital japonês, foi recorrente a substituição dos núcleos gestionários por brasileiros natos. Ademais, a posição 
do Japão como inimigo de guerra da nação brasileira difundiu sentimentos de intolerância contra os imigrados e promoveu o policiamento de suas atividades. A sericicultura subsistiu como principal atividade econômica do município até 1945, quando sofreu um declínio e deu lugar à avicultura - que, atualmente, destaca Bastos no setor agrícola brasileiro (MARUYAMA, 2011).

Nesse processo de diversificação da produção, as cooperativas agrícolas tiveram importância fundamental, pois ofereceram alternativas viáveis aos produtores rurais. Basicamente, elas dispunham de um sistema mais integrado de assistência à produção e de comercialização. Logo após o fim da guerra, algumas cooperativas instalaram escritórios e depósitos no município: a Cooperativa Agrícola Bandeirante (1946), a Cooperativa Agrícola de Cotia (1947), a Cooperativa Agrícola de Juqueri (1951).

A partir de 1947, as candidaturas aos cargos municipais foram lançadas, majoritariamente, por uma segunda geração, nascida no Brasil, ou mesmo naturalizada. Referidos pelos entrevistados como "ala jovem" dos imigrantes, esses candidatos de segunda geração se valeram do apoio de associações - em especial, as cooperativas - para alcançar a aprovação de sua candidatura política.

Conforme mencionado anteriormente, elas representavam um dos principais espaços de sociabilidade dos imigrantes. Em municípios formados a partir de núcleos coloniais, isso ocorria até mesmo com mais intensidade. Portanto, certos capitais sociais decorrentes da senioridade, da experiência migratória anterior e da presença ativa em associações foram fatores impulsionadores de candidaturas ${ }^{26}$.

As associações fundadas por japoneses em Bastos se estabeleceram em 1930, com a criação da Bastos-kai. Ela foi uma das diversas entidades de caráter social que foram fundadas na colônia, mas que se distinguiu por possuir a sua memória preservada por ter se desdobrado na atual Associação Cultural e Esportiva NipoBrasileira de Bastos. Além da Bastos-kai, havia ainda outras entidades, como as equipes esportivas, os grupos teatrais, igreja, associação de moços, além da escola primária e do hospital. Muitas delas eram formadas a partir de afinidades da província de origem ou a partir das seções produtivas da colônia.

A singularidade da Bastos-kai é que, a partir de 1933, ela ampliou o escopo de suas atividades e, com a aprovação da Bratac, foi reformulada sob o nome Jitikai (Associação Independente). Em 1939, um importante movimento organizacional ocorreu: o Jitikai foi incorporado pela Sociedade Cooperativa de Bastos Cooperativa Central. A chefia dessa cooperativa foi composta por Senjiro Hatanaka (considerado pelos japoneses como o fundador de Bastos) e Jinsaku Wakiyama, assassinado em 1946.

\footnotetext{
${ }^{26}$ Informações obtidas por meio da entrevista com um ex-candidato a prefeito de Bastos, realizada em agosto de 2018.
} 
Na Jitikai, cada uma das seções territoriais possuía um chefe e um subchefe que representavam os interesses dos colonos das seções. Cada seção, por sua vez, possuía uma associação própria, que elegia esses representantes (MITA, 1999). Assim, a forma de organização colonial ali existente favoreceu a formação de lideranças locais entre os colonos. Justamente, algumas dessas lideranças destacaram-se no cenário político a partir de 1947. Mesmo que a vinculação a associações não fosse algo indispensável para a eleição de candidatos, foi constatado que, internamente aos núcleos coloniais, ela representou um importante mecanismo relacional, capaz de aumentar as chances de inserção desses sujeitos nas estruturas de poder em âmbito municipal.

\section{Espaços de sociabilidade e recursos}

Os candidatos eleitos a partir de 1947 guardaram estreito diálogo com as associações locais de forma a mobilizar apoio político. Podemos mencionar, por exemplo, o caso de Senjiro Hatanaka: além de ter trabalhado para o Consulado e ser considerado o fundador do município, na década de 1960, foi condecorado tanto pelo governo brasileiro quanto pelo governo japonês. No final de sua vida, ocupou cargos na representação local da Cooperativa Agrícola de Cotia. O seu filho, Tadao Hatanaka, ocupou cargos na Sociedade Cooperativa de Bastos e, em 1956, foi eleito prefeito - o primeiro de origem japonesa eleito em toda a história do estado de São Paulo.

A candidatura deste último, dificilmente, teria sido viabilizada sem o suporte e a aprovação das lideranças japonesas mais antigas e das lideranças de seções. Isso porque, especialmente em núcleos coloniais geridos pela Bratac, como é o caso de Bastos, a noção de pertença havia sido reconfigurada na jornada migratória e assumiu características singulares. Na leitura do antropólogo Takashi Maeyama (1979), as colônias representariam uma espécie de exclave da nação japonesa, esta última que possuiria primazia, mesmo em relação às preferências individuais: “A colônia japonesa nas décadas de 1920 e 1930 era, por assim dizer, um tobichi (um território separado, um exclave), uma parte suplementar da nação japonesa. Os imigrantes formavam uma estrutura única por causa do Japão, mas não por si mesmos". (MAEYAMA, 1979, p.593).

Para este autor, o sentimento de unidade nacional japonesa em terras brasileiras era fomentado, principalmente, pelo Consulado Geral do Japão em São Paulo, entidade oficial de representação do regime imperial. A ele se somavam a empresa de imigração Kaigai Kogyo Kabushiki Kaisha e a empresa de administração colonial Bratac. Esses três órgãos, de modo interrelacionado, centralizavam os principais instrumentos de amparo às atividades exercidas pelos imigrados e, por 
isso, passaram a ser considerados por estes últimos como os representantes locais das "três famílias reais" (go-sanke) - superintendentes hereditários feudais do xogunato Tokugawa a quem os súditos do imperador estariam subordinados.

Nas colônias, havia, assim, um sistema social emulado e organizado em torno de um centro de poder soberano. Ele era pouco suscetível a mudanças, mas devido a circunstâncias adversas já explicitadas, em fins dos anos 1930, foi desestabilizado e progressivamente abandonado. Contudo, durante anos esse sistema regeu a vida cotidiana de muitos imigrantes de primeira geração e seus descendentes e instaurou lógicas de sociabilidade com apreço pela senioridade.

Portanto, ao menos até 1956, quando Tadao Hatanaka foi eleito prefeito, a influência dos imigrantes mais experientes regia as chances de sucesso no campo político. Em contraposição, em sua gestão, Hatanaka já anunciava a existência de uma clivagem geracional no ambiente das lideranças de Bastos: "Indiferentes em relação à Câmara Municipal, como estão, os japoneses de Bastos serão vistos como irresponsáveis. Gostaria que os japoneses de Bastos, em especial os da geração de 40 anos, se naturalizassem e se candidatassem a vereador". (HATANAKA, 2011, p.307).

Na visão do prefeito, os imigrantes de primeira geração possuíam certa indiferença em relação à sua presença no debate público municipal, pois em geral costumavam lidar com assuntos de ordem coletiva no âmbito restrito dos núcleos coloniais. Assim, o advento da estrutura de poder em nível municipal trouxe a essas lideranças uma espécie de desafio de adequação, assumido, principalmente, por indivíduos de segunda geração e, em menor grau, por imigrantes naturalizados. Ademais, o forte vínculo dos japoneses com a terra natal aparenta ser, em sua avaliação, algo incompatível com o cenário político de autonomia municipal que então passava a vigorar.

Após a gestão de Hatanaka, a projeção das lideranças de segunda geração filhos de imigrantes ainda continuou se valendo do suporte de associações de primeira geração. Mas a clivagem geracional por ele apontada, também, indicava a importância de outros espaços demarcados justamente pela idade, idioma e escolaridade, como a associação de moços (seinenkai). Em meados da década de 1950, esta já representava um importante espaço de sociabilidade capaz de arregimentar apoio político, competindo com as associações frequentadas pela primeira geração, conforme revelou um entrevistado que ocupou os cargos de vereador e prefeito nas décadas de 1960 e 1970: "Quem começou participando ativamente do seinenkai foi o (Tohoru) Nishi (eleito vereador em 1955 e prefeito em 1959). Eu e Nishi fomos presidente do seinenkai. Politicamente, isso ajudou bastante"27.

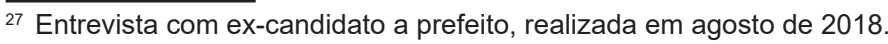


Deve-se ressaltar que, em Bastos, entre 1947 e 1968, a candidatura de filhos de japoneses para a prefeitura era única, ou seja, feita com base em acordo entre as lideranças locais. Segundo esse acordo, não havia mais de um candidato de origem japonesa para o cargo de prefeito. As candidaturas a prefeito e vereador eram, também, endossadas política e financeiramente pela Associação Cultural e Esportiva Nipo-Brasileira de Bastos, conforme relato sobre as eleições de 1959 (USAMI, 2011, p.121).

Além da necessidade de garantir o apoio de descendentes mediante uma origem social compartilhada, na década de 1950 o cenário político se complexou, mostrando a importância decisiva do eleitorado nativo, sem origem imigrante. Nesse sentido, o entrevistado revelou que, ao menos em sua candidatura, esse eleitorado se mostrou decisivo: "Nikkei (descendente de japoneses) preferencialmente votava em nikkei. Preferencialmente. Mas em cada eleição algumas coisas influem. Devido à minha posição eu conquistei, sem pretensão, a simpatia de gaijins (aquele que não possui descendência japonesa)" ${ }^{28}$. O contato com esse público dependia de recursos que, principalmente, a segunda geração possuía, como a escolaridade e o domínio do idioma português.

Em suma, em um primeiro momento, entre as lideranças locais predominavam indivíduos que mantinham fortes laços institucionais e culturais com o país de origem. Já em fins da década de 1940, as lideranças de segunda geração (ou mesmo as de primeira geração naturalizadas) buscaram adequar o sistema de organização coletiva prevalecente no ex-núcleo colonial à recém-estabelecida estrutura de poder público municipal. No período considerado, os candidatos que lograram êxito nos pleitos municipais se caracterizaram por converter seu capital social circunscrito pela origem japonesa em qualidade impulsionadora de um perfil político profissional.

\section{Considerações finais}

Este estudo buscou demonstrar, em um período específico da história republicana, a qualidade explicativa de fatores estruturais e relacionais na tarefa de examinar o acesso de indivíduos de origem japonesa às esferas de poder e decisão política. Os resultados alcançados pela pesqusia fornecem subsídios para o aprimoramento da caracterização histórica da sociedade paulista, em especial no que se refere à sua capacidade de ofertar oportunidades institucionalizadas a grupos estrangeiros, à quebra de fronteiras simbólicas relativas à sua aceitação e à renovação de grupos políticos.

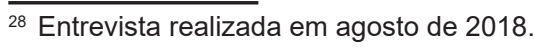


Se considerarmos, por um lado, a existência de impedimentos - valorativos e institucionais - experimentados pelos japoneses na sociedade paulista ao longo das primeiras décadas desde o início de sua jornada migratória, por outro, a eleição de candidatos dessa origem (principalmente, indivíduos de segunda geração, filhos de imigrantes nascidos no Brasil) evidencia-se a transformação paulatina desse cenário. Sob essa perspectiva, a inserção política é uma modalidade específica de incorporação, um fenômeno catalisador de transformações nas formas de organização coletiva da sociedade receptora. A sua análise complementa o entendimento dos processos de mobilidade socioeconômica de imigrantes.

O exame detido sobre a composição das legislaturas de municípios do estado de São Paulo no período considerado demonstra que grande parte dos casos de candidatos de origem japonesa eleitos esteve concentrado em localidades onde a presença de imigrantes foi expressiva. A convergência desses dois fenômenos, dificilmente, ocorreu de modo aleatório e a sua interpretação demanda considerar duas características próprias a essa população: a primeira delas é a sua dinâmica espacial, ou seja, movimentos de migração inter-regionais tendo em vista a exploração de áreas agrícolas situadas à Oeste do estado; a segunda se refere a uma tendência geral de mobilidade ocupacional ascendente, experimentada pela maior parte dessa população durante a primeira metade do século vinte. Ambas características se valeram de arranjos institucionais nos estados de origem e acolhimento, pois estes forneceram as condições mais gerais para o estabelecimento do contingente imigrado, majoritariamente, dedicado a atividades agrícolas.

No período considerado, o município de Bastos concentrou a ocorrência de candidatos eleitos. Ali, os órgãos representativos do governo japonês (assim como o capital privado oriundo de empresas japonesas) foram decisivos na criação de uma rede de suporte ao imigrado. Sob forte incentivo consular, as cooperativas agrícolas se destacaram nesse aspecto, pois no plano econômico viabilizaram as chances de mobilidade ascendente. Outrossim, esse tipo de empreendimento, também, operou no universo simbólico, ao assumir a posição de autoridade cultural.

Os dados obtidos, também, indicam a existência de uma variedade de posições sociais e visões de mundo entre os candidatos eleitos, o que representa uma diversidade social - interna à população japonesa - por vezes pouco considerada. Entre todos os candidatos que disputaram eleições (dos quais não temos registros a respeito dos que não se elegeram) somente alguns deles, posicionados, estrategicamente, e fazendo uso de recursos significativos, puderam efetivar uma inserção na estrutura local de poder.

No caso de Bastos, candidatos eleitos guardaram estreito diálogo com entidades associativas locais de forma a mobilizar apoio político. Elas representaram um importante mecanismo relacional, um esteio sem as quais esses sujeitos, dificilmente, lograriam êxito em suas candidaturas. No período considerado, que comportou a 
mudança de regime político e, internamente aos japoneses, uma transição geracional e de sistema de valores, os recursos associativos étnicos se mostraram mais proeminentes se comparados às formas convencionais de representação política, como organizações partidárias e sindicais.

Por fim, espera-se que este estudo contribua para o debate sociológico interessado em migrações históricas e auxilie na elaboração futura de um quadro interpretativo mais amplo, capaz de relacionar processos de mudanças de fronteiras étnicas a partir da comparação de grupos de diferentes origens.

\section{CANDIDATES OF JaPANESE ORIGIN IN THE STATE OF São PaUlo's municipal elections, 1947-1964}

ABSTRACT: This article seeks to describe the mechanisms which contributed to the election of Japanese-origin candidates in the state of São Paulo municipal elections between 1947 (when the first state and municipal elections take place since the beginning of the Estado Novo regime) and 1964 (when the democratic regime was interrupted). Data records from the Regional Electoral Court were collected in order to identify the candidates who occupied the chairs of Councilor, Mayor and Deputymayor. The relationship between candidacies and strategic relational resources from ethnic social spaces is also demonstrated. This case study was carried out in Bastos.

KEYWORDS: Japanese immigration. Immigration. Japanese immigrants. Political participation. Elections.

\section{Candidatos de origen JAPONÉS EN LA POLÍtica MUNICIPAL de SÃo PaUlo, 1947-1964}

RESUMEN: Este trabajo busca caracterizar las condiciones que posibilitaron la elección de hijos de descendientes de japoneses para las esferas de poder y decisión política en los municipios del estado de São Paulo entre 1947 (cuando se realizaron las primeras elecciones a nivel estatal y municipal desde el inicio del periodo del Estado Novo) y 1964 (cuando se interrumpió el régimen político democrático). Los datos sobre la ocupación de los cargos legislativos (concejales) y ejecutivos (alcaldes y vicealcaldes) se elaboraron a partir de los datos electorales agregados puestos a disposición por el Tribunal Electoral Regional/SP. Se demuestra la relación entre las candidaturas y los recursos relacionales procedentes de los espacios sociales étnicos. El estudio de caso se realizó en el municipio de Bastos.

PALABRAS CLAVE: Inmigración japonesa. Elecciones. Japonés. Inserción política. São Paulo. 


\section{REFERÊNCIAS}

AVRITZER, Leonardo. O pêndulo da democracia no brasil: uma análise da crise 2013-2018. Novos Estudos CEBRAP, v. 37, n. 2, p.273-289, 2018.

BASTOS, Associação Cultural e Esportiva Nipo-Brasileira De. Livro histórico de 80 anos da imigração nikkei de Bastos. [S.l: s.n.], 2011.

BAUAB, José D'Amico. A primeira eleição ao parlamento paulistano pós-ditadura Vargas e o drama dos vereadores comunistas. In: MANECHINI, L. C. (Org.). São Paulo na Tribuna : primeira legislatura (1948-1951)/Escola do Parlamento da Câmara Municipal de São Paulo. São Paulo: Imprensa Oficial do Estado de São Paulo, 2012. p.25-48.

BERTOLDO, Ricardo Vieira. A trajetória política dos nikkeis em Mairinque. Dissertação de Mestrado. Faculdade de Filosofia, Letras e Ciências Humanas. Universidade de São Paulo - USP, 2018.

BLALOCK, Hubert M. Toward a Theory of Minority-Group Relations. New York: John Wiley \& Sons, 1967.

BONACICH, Edna. A Theory of Middleman Minorities. American Sociological Review, v. 38, n. 5, p.583-594, 1973.

BOURDIEU, Pierre. O capital social - notas provisórias. In: CATANI, A.; NOGUEIRA, M. A. (Org.). Escritos de Educação. Petrópolis: Vozes, 1998. p.65-70.

CODATO, Adriano. A formação do campo político profissional no Brasil: uma hipótese a partir do caso de São Paulo. Revista de Sociologia e Política, v. 16, n. 30, p.89-105, 2008.

COMISSÃO DE ELABORAÇÃO DA HISTÓRIA DOS 80 ANOS DA IMIGRAÇÃO JAPONESA NO BRASIL. Uma epopeia moderna: 80 anos da imigração japonesa no Brasil. São Paulo: Hucitec, 1992.

DEZEM, Rogério. Shindô Renmei, terrorismo e repressão. São Paulo: Arquivo do Estado/ Imprensa Oficial, 2000.

ENNES, Marcelo A. Imigração e direitos na região noroeste paulista. Estudos de Sociologia, v. 12, n. 1, p.53-78, 2006.

FAUSTO, Boris. Historiografia da imigração para São Paulo. São Paulo: Idesp/Editora Sumaré, 1991.

FAUSTO, Boris; TRUZZI, Oswaldo Mario Serra; GRÜN, Roberto; SAKURAI, Célia. Imigração e política em São Paulo. São Paulo: Sumaré, 1995. 
GERSTLE, Gary; MOLLENKOPF, John (Org.). E Pluribus Unum? Contemporary and Historical Perspectives on Immigrant Political Incorporation. New York: Russell Sage Foundation, 2001.

GREEN, Nancy L. Time and the study of assimilation. Rethinking History, v. 10, n. 2, p.239-258, 2006.

GUIMARAES, Antonio Sérgio Alfredo. Depois da democracia racial. Tempo Social, v. 18, n. 2, p.269-287, 2006.

HATANAKA, Maria Lucia Eiko. O processo judicial da "Shindo-Remmei": um fragmento da historia dos imigrantes japoneses no Brasil. Dissertação de Mestrado. Pontifícia Universidade Católica de São Paulo, 1993.

HATANAKA, Tadao. Autocrítica de Bastos / O defeito de Bastos é o defeito de todos os japoneses. In: BASTOS, ASSOCIAÇÃO CULTURAL E ESPORTIVA NIPO-BRASILEIRA DE (Org.). Livro histórico de 80 anos da imigração nikkei de Bastos. 2011, p.305-310.

KANTOWICZ, Edward R. Polish-American Politics in Chicago, 1880-1940. Chicago: University of Chicago Press, 1975.

LEVY, Maria Stella. O papel da migração internacional na evolução da população brasileira (1872-1972. Revista de Saúde Pública, v. 8, p.49-90, 1974.

LIGHT, Ivan. Ethnic Enterprise in America: Business and Welfare Among Chinese, Japanese, and Blacks. Berkeley: University of California Press, 1972.

MAEYAMA, Takashi. Ethnicity, Secret Societies, and Associations: The Japanese in Brazil. Comparative Studies in Society and History, v. 21, n. 4, p.589-610, 1979.

MANEChINI, Luiz Casadei (Org.). São Paulo na Tribuna : primeira legislatura (1948-1951). São Paulo: Imprensa Oficial do Estado de São Paulo, 2012.

MARUYAMA, Sakae. História da fiação de Seda Bratac: a força do desenvolvimento de Bastos e a liderança da indústria de seda no Brasil. In: BASTOS, ASSOCIAÇÃO CULTURAL E ESPORTIVA NIPO-BRASILEIRA DE (Org.). Livro histórico de 80 anos da imigração nikkei de Bastos. 2011. p.50-87.

MITA, Chiyoko. Bastos: uma comunidade étnica japonesa no Brasil. São Paulo: Humanitas, 1999.

NAGAMURA, Yukako. A cobertura dos jornais japoneses na campanha eleitoral dos políticos nipo-brasileiros: Nikkey Shimbun e São Paulo Shimbun (1998-2014). Dissertação de Mestrado. Programa de Pós-Graduação em Sociologia. Ciências Humanas Letras e Artes, Universidade Federal do Paraná, 2015. 
NEE, Victor; DE BARY NEE, Brett. Longtime Californ: a documentary study of an American Chinatown. New York: Pantheon Books, 1973.

NOGUEIRA, Arlinda Rocha. A imigração japonesa para a lavoura cafeeira paulista (1908-1922). São Paulo: Instituto de Estudos Brasileiros, 1973.

PORTES, Alejandro. Capital social: origens e aplicações na sociologia contemporânea. SOCIOLOGIA, PROBLEMAS E PRÁTICAS, v. vi, p.133-158, 2000.

PORTES, Alejandro. One Field, Many Views: Competing Theories of International Migration. In: FAWCETTAND, J.; CARIÑO, B. (Org.). Pacific Bridges: The New Immigration from Asia and the Pacific Island. Center for ed. New York: [s.n.], 1987. p.53-70.

PORTES, Alejandro. 13 Modes of Structural Incorporation and Present Theories of Labor Immigration. International Migration Review, v. 15, n. 1, p.279-297, 1981.

PORTES, Alejandro; MANNING, Robert. The immigrant enclave: Theory and empirical examples. In: OLZAK, Susan; NAGEL, Joanne (Org.). Comparative Ethnic Relations. New York: Academic Press, 1986. p.47-68.

PORTES, Alejandro; RUMBAUT, Ruben (Org.). Immigrant America: A Portrait. 1. ed. Los Angeles: University of California Press, 1990.

PORTES, Alejandro; SENSENBRENNER, Julia. Embeddedness and immigration: notes on the social determinants of economic action. American Journal of Sociology, v. 98, n. 6, p.1320-1350, 1993.

PORTES, Alejandro; ZHOU, Min. The New Second Generation : Segmented Assimilation and Its Variants. The Annals of the American Academy of Political and Social Science, v. 530, p.74-96, 1993.

SAITO, Hiroshi. O Japonês no Brasil: estudo de mobilidade e fixação. São Paulo: Ed. Sociologia e Política, 1961.

SAKURAI, Celia. Os primeiros políticos de origem japonesa no Brasil. Acervo histórico, n. 4, 2005.

SAKURAI, Celia. Descendentes de japoneses e participação política - perfil de quatro políticos. $\mathbf{1 7}^{\circ}$ Encontro Anual da ANPOCS, Caxambu, 1993.

SALVADORI FILHO, Fausto.- PERFIL - YUKISHIGUE TAMURA. A felicidade do pioneiro. Apartes, n 05, jan-fev, p.17-24, 2014. Disponível em: https://www.saopaulo.sp.leg. br/apartes-anteriores/revista-apartes/numero-5-janeiro-fevereiro2014/no05-a-felicidade-dopioneiro/. Acesso em: 06 abr. 2021. 


\section{Gustavo Takeshy Taniguti}

SCHILLER, Nina Glick. Beyond Methodological Ethnicity: Local and Transnational Pathways of Immigrant Incorporation. Willy Brandt Series of Working Papers in International Migration and Ethnic Relations, n. 2, p.1-37, 2008.

SEABRA, Manoel. As cooperativas mistas do Estado de São Paulo. Série tese ed. São Paulo: IGEOG, 1977.

SOUZA, Maria do Carmo Campello De; KERBAUY, Maria Teresa Miceli; TRUZZI, Oswaldo Mário Serra. Do clientelismo coronelista ao clientelismo de Estado: a ascensão de imigrantes na política do interior paulista. Perspectivas: Revista de Ciências Sociais, v. 26, p.11-34, 2003.

SUZUKI, Teiiti. The Japanese Immigrant in Brazil. Narrative part. Tokyo: University of Tokyo, 1969.

TANIGUTI, Gustavo T. Cotia: imigração, política e cultura. São Paulo: Annablume, 2019.

TANIGUTI, Gustavo T. Imigrantes japoneses e mercado de trabalho agrícola em São Paulo. In: CARNEIRO, MARIA LUIZA TUCCI; HIRANO, SEDI (Org.). Histórias Migrantes: um mosaico de nacionalidades e múltiplas culturas. São Paulo: Humanitas, 2014. p.165-202.

TRUZZI, Oswaldo. Assimilação ressignificada: novas interpretações de um velho conceito. Dados, v. 55, n. 2, p.517-553, 2012.

TRUZZI, Oswaldo. Patrícios: sírios e libaneses em São Paulo. São Paulo: Editora UNESP, 2009.

TRUZZI, Oswaldo; KERBAUY, Maria Teresa Miceli; BARBOSA, Agnaldo de Souza. Mudança de fronteiras étnicas e participação política de descendentes de imigrantes em São Paulo. Revista Brasileira de Ciências Sociais, v. 27, n. 80, p.135-151, 2012.

USAMI, Soichi. Os 80 anos da caminhada da Associação Cultural e Esportiva Nikkey de Bastos. Livro histórico de 80 anos da imigração nikkei de Bastos. [S.1.]: Associação Cultural e Esportiva Nipo-Brasileira de Bastos, 2011. p.88-144.

WILLEMS, Emílio; SAITO, Hiroshi. Shindô-Renmei: um problema de aculturação. Sociologia, v. 9, n. 2, p.133-152, 1947.

Recebido em 19/02/2020.

Aprovado em 17/02/2021. 